REPERTÓRIO

LIVRE

\title{
OS CAMINHOS DO CURSO DE DANÇA DA UNICRUZ (1998-2010)
}

\author{
THE PATHS OF THE DANCE COURSE \\ OF UNICRUZ (1998-2010)
}

CARMEN ANITA HOFFMANN

ANDRISA KEMEL ZANELLA

DÉBORA SOUTO ALLEMAND

HOFFMANN, Carmen Anita; ZANELLA, Andrisa Kemel; ALLEMAND,

Débora Souto.

Os caminhos do curso de dança da Unicruz.

Repertório, Salvador, ano 22, n. 32, p. 321-343, 2019.1 


\section{RESUMO}

O presente texto tem por objetivo visibilizar analiticamente o percurso institucional do Curso de Dança - Licenciatura Plena da UNICRUZ (1998-2010), em Cruz Alta, Rio Grande do Sul. Para isso, apresenta o seu processo histórico, o pioneirismo, a inserção e relevância para o Estado, especialmente no que se refere à formação superior em Dança, bem como suas repercussões na instalação de outros sete Cursos. A pesquisa caracteriza-se como qualitativa e adota a metodologia da história oral, utilizando como principal instrumento entrevistas semiestruturadas com exprofessores, ex-alunos e pessoas envolvidas. Embora o Curso tenha se consolidado e contribuído para os avanços nos estudos de dança no Rio Grande do Sul, em 2010 formou a última turma. Esses acontecimentos não o aniquilam, eles o tornam inteligível ao percebermos as relações de um Curso com seu tempo. A análise das memórias permitiu avaliar que o curso seguiu uma trajetória consoante às condições do contexto em que se desenvolveu. A história do Curso de Dança da UNICRUZ representa um marco na história da educação superior em Dança no Estado.

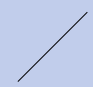

ABSTRACT

This paper analyzes and seeks to understand the institutional trajectory of UNICRUZ Dance Course Full Degree (1998-2010). It presents its historical process, pioneering, insertion and relevance for the State of Rio Grande do Sul, especially about higher education in dance. The research is characterized as qualitative and adopts the methodology of oral history, using as main instrument semi-structured interviews with ex-teachers, ex-students and people involved. Although the Course has been consolidated and contributed to advances in dance studies in Rio Grande do Sul, in 2010 formed its last group. These events do not annihilate the Course, they make it intelligible when we notice the relationship of a Course with its time. The analysis of the memories gave the possibility to evaluate that the course followed a trajectory depending on the conditions of the context in which it was developed. The history of the Course of Dance UNICRUZ represents a milestone in the history of the academical degree in Dance in Rio Grande do Sul, as since its creation, there were settled seven other courses in the State.

\section{Palavras-chave: Cruz Alta/RS. 1998-2010. Graduação em Dança, história, Universidade de Cruz Alta.}

\section{KEYWORDS:}

Cruz Alta/RS. 1998-2010.

Dance Degree Course, history, University of Cruz Alta. 


\section{A FORMAÇÃo SUPERIOR EM DANÇA NO BRASIL possui}

mais de meio século no âmbito acadêmico, mas, entre a fundação do primeiro curso em 1956 - a Escola de Dança na Universidade Federal da Bahia (UFBA) -, e a expansão dessa situação, houve um hiato de praticamente três décadas quando da instalação do segundo curso, que foi em 1984, na Faculdade de Artes do Paraná (FAP). Com isso pôde-se perceber que a formação superior em dança no Brasil não seguiu uma linha uniforme, pois, como confirma o último Fórum de Coordenadores de Cursos Superiores de Dança no Brasil, em agosto de 2014, foram identificados 45 cursos no país, dentre os quais 13 bacharelados e 32 licenciaturas.

A partir dessa expansão do ensino superior, a área de conhecimento que compreende a dança começou a conquistar outros espaços de atuação, sendo mais reconhecida e com possibilidades de desenvolvimento em seus estudos práticos e teóricos. Como fenômeno social, assume uma complexidade que se espraia por diferentes setores da sociedade, despertando interesse em outras áreas de conhecimento e como objeto de estudo de várias ciências.

Os problemas aqui lançados dialogaram com as inquietações presentes nesta investigação, cujo foco foi o de abordar a história do Curso de Dança da Universidade de Cruz Alta (UNICRUZ), no período entre 1998 e 2010, a partir de suas memórias, pois o mesmo se constituiu como uma referência na área da dança no Estado do Rio Grande do Sul, por ter sido o primeiro e por ter formado profissionais prestigiados pelo mercado e pela sociedade. 
No decorrer dos seus 13 anos de existência, o Curso de Dança da UNICRUZ, no

município de Cruz Alta/RS, através das suas atividades de ensino, pesquisa e extensão, consolidou um projeto pedagógico que contemplou a formação de profissionais - agentes de mudanças - preocupados com o futuro da dança na sociedade, sua legitimação e reconhecimento em todas suas instâncias.

Diante desse contexto, optou-se por investigar o processo de constituição da memória através dos sujeitos que vivenciaram o Curso, por isso, ao definir o objeto, buscou-se valorizar aquela comunidade acadêmica, analisar as particularidades do grupo e entender como no presente produzem esse passado vivido naquele contexto. A pesquisa nasce da necessidade de entender a razão e o sentido daquele projeto, aquele grupo de professores, alunos e pessoas envolvidas naquele lugar e naquele tempo delimitado pela própria trajetória e o desdobramento do seu fechamento, onde os sujeitos que estiveram envolvidos nesse coletivo que criou esse Curso se voltam para a construção de seu projeto individual que a nova realidade possibilita.

Para tanto, almejou-se identificar as razões que atuaram na sua origem e em que contexto surgiu. Além de buscar descrever os pressupostos que deram corpo ao Curso, compreender os motivos para o seu fechamento, a partir da memória dos sujeitos envolvidos nesse projeto, ensejados nos discursos dos ex-coordenadores, ex-professores, ex-alunos e alguns terceiros envolvidos nas atividades do mesmo.

O recorte temporal desta pesquisa compreendeu o período de 1998 a 2010. Cabe ressaltar que o Curso teve um período que antecedeu a sua implantação: o de pesquisa de mercado e tentativas de implantação, mas, mesmo que a sua aprovação tenha ocorrido em 1994, sua inauguração com o ingresso da primeira turma ocorreu somente em 1998. O limite final se estabeleceu em função da descontinuidade quando da formatura da última turma, em 2010.

Considera-se importante a abordagem de estudos históricos no âmbito da dança, pois não se pode continuar a ter e divulgar uma visão romântica da dança, principalmente quando se tem a necessidade de repensar o ensino superior nessa área de conhecimento. A percepção de uma leitura histórica do Curso de Dança da UNICRUZ, enquanto incubador de ideias, implica em uma reinterpretação de 
fontes do passado no que se refere à interdisciplinaridade e à organização metodológica. E, neste sentido, Strazzacappa (2012, p. 62), coloca que na construção do conhecimento em dança, a realidade brasileira apresenta problemas no ensino de dança e destaca alguns pontos que se associam à demanda aqui pautada:

1) A existência de leis específicas que incluem a dança como atividade obrigatória nos currículos escolares não garante o ensino da dança nas escolas.

2) A dança é historicamente a última na lista das linguagens artísticas presentes na escola. Artes visuais, música e teatro costumam anteceder a escolha pela dança.

3) O ensino da dança continua sendo possivel pela ação de pessoas apaixonadas, que acreditam na dança e que reconhecem a dança como área de conhecimento, logo, como um saber essencial na formação do cidadão. [...] Aqui a palavra apaixonada não pode ser vista no sentido pejorativo, mas como dedicação, crença.

A autora propõe que se busquem soluções e caminhos no que diz respeito à diversidade da dança e que é um momento histórico importante porque a classe está se organizando, mas alerta para que se continue atento:

Nem todas as batalhas foram ganhas e muitas ainda continuam em processo. Acreditamos na relevância dessa iniciativa por possibilitar aos interessados a imersão no atual contexto da dança; por acordar os adormecidos; por incitar os despercebidos e estimular os empenhados que acreditam na dança e na sua importância para a educação. (STRAZZACAPPA, 2012, p. 124)

Ao direcionar o olhar para um curso superior que propagou saberes específicos da área de dança em espaços formais e não formais de ensino, aposta-se na visibilização de um processo de legitimação da dança como área e conhecimento fundamental na constituição do saber humano. Assim, inserimo-nos no processo de consolidação e propagação da dança no panorama atual brasileiro. 
Com a compreensão de que é necessário o aporte teórico-metodológico alicerçado na história para compreender a inauguração da formação em dança no Rio Grande do Sul, a escolha se justifica por ser mais adequada e possibilitar novos questionamentos que despertam outros saberes. Os estudos da história social, de memória e de história oral, as leituras de diferentes pensadores, ainda que instiguem muitas indagações, permitem estabelecer novos entendimentos para a ciência, dos sujeitos, do campo, da história e da dança. O desejo dessa compreensão encontrou, nos outros, a oportunidade de manifestação e é este o motivo que levou a se passar um grande tempo consultando arquivos, buscando pistas e copiando informações, buscando agendas e realizando entrevistas intercaladas com os quilômetros percorridos entre Pelotas - Porto Alegre - Cruz Alta e, inclusive, dirigindo-se até Joinville, em Santa Catarina e Salvador, na Bahia. ${ }^{1}$ E, após tudo isso, foi a vez das transcrições infindáveis onde se criaram e se recriaram memórias.

Na elaboração da pesquisa se buscou subsídios no campo histórico, por ter este uma trajetória sistematizada e cumulativa nos estudos sobre memória e história oral. De acordo com Cerbino (2005, p. 56), ao historiador da dança cabe,

[...] além da seleção previamente realizada, ou ainda a ser feita, sobre determinado tema, o papel de cronista e intérprete, recriando o passado por meio da descrição e da narrativa, e, ao mesmo tempo, interpretando-o através de técnicas de análise.

O tema e o objeto deste trabalho estão ligados aos estudos da história da cultura, das instituições e da memória. As abordagens das memórias e, especialmente com os depoimentos dos sujeitos, por intermédio da história oral, permitem uma dimensão singular na relação com tempo vivido e delimitado. As entrevistas suscitaram uma revisita e novas formas de compreensão do passado, buscando apontar em que medida a criação do Curso de Dança da UNICRUZ foi importante para o ensino da dança no Rio Grande do Sul, como se deu a trajetória desse Curso, sua emergência, implantação, consolidação e descontinuidade e quais foram os desdobramentos do Curso no âmbito do Rio Grande do Sul.

O Curso de Dança da UNICRUZ foi criado em um contexto e em um tempo onde foi permitido e possibilitado a sua implantação, onde a Universidade de Cruz Alta

1 Em Porto Alegre e Cruz Alta, encontram-se a maioria dos entrevistados e, alguns em Pelotas. Em Joinville foi possível encontrar entrevistado que reside em Curitiba, cuja agenda é complexa, sendo mais acessível, o Otávio Nassur (professor de hip hop que participou diversas vezes das ações do Curso de Dança da Unicruz). Em Salvador, em função do encontro de uma das avaliadoras do Instituto Nacional de Estudose Pesquisas Educacionais Anísio Teixeira Ministério da Educação (INEP/MEC), Maria da Conceição Castro e da ex-aluna de Cruz Alta, mestranda da UFBA Lígia Martins. 
acabou por encampar a ideia inovadora. Por ser um espaço acadêmico, o Curso foi

engendrado dentro das normas e prerrogativas estabelecidas pelo MEC, transformando-se em referência no ensino superior em Dança no Estado. Sua articulação com as instâncias estaduais de Educação e Cultura permitiram, de certo modo, o reconhecimento da qualidade dos profissionais egressos, bem como dos alunos egressos desse Curso. Por tudo isso, a sua história se vincula à própria história da dança no Rio Grande do Sul.

Consciente de que a fonte oral, como toda a fonte histórica, não se trata de uma prova da realidade, mas sim como indiciária para a procura de uma compreensão mais apurada, buscou-se provocar os sujeitos, cujos depoimentos são marcados pelo tempo presente, pois os fatos partem do presente e vão sendo expostos por lembranças registradas de interesses. Nessa perspectiva refletiu-se sobre história oral baseando-se em Constantino (2004) e Alberti (2005), para compreender o estudo das formas de como as pessoas elaboraram as experiências de recuperação da memória e da utilização da fonte oral. Em Aliança (2011), para entender no processo do relato autobiográfico, onde o sujeito distancia-se de si mesmo. Por fim, Portelli (2010) contribuiu para o entendimento que na história oral, o relato da história não é um fim em si mesmo.

Foi em Chartier (2001) que se buscou relacionar as perdas de unidade das tradições historiográficas, as fragmentações entre perspectivas diversas, enfim, o abandono de um modelo dominante. Para tanto é sabido que é preciso considerar os limites teórico-metodológicos de qualquer investigação, pesquisador e as articulações objeto/campo do conhecimento, de onde decorre o acabamento não definitivo e sim alternativo de uma investigação.

Nesse caso, estudando a memória, constata-se que é um referencial importante e pode ser percebida como em permanente estado de mudança e transformação. Tem-se, então, um movimento de lembrança e esquecimento capaz de gerar novas configurações do passado. Eé Cerbino (2005, p. 65) que ressalta a possibilidade da história da dança alçar novos voos, com um corpo teórico que a sustente, a partir da produção do social, como espaço necessário para se pensar a história cultural. 
Procurou-se trabalhar com as memórias das vivências do Curso, sendo elas fragmentárias, coletivas e imprevisíveis. Deste modo, então, buscou-se analisar elementos que contribuíram para a consolidação do Curso de Dança da UNICRUZ e procurou-se, ainda, visualizar os procedimentos que contribuíram para que houvesse a descontinuidade do mesmo e entender os processos do presente em outros comprometimentos institucionais.

Compor as memórias do Curso foi uma forma de compreender seu funcionamento tanto no contexto acadêmico como no profissional, especificamente naquilo que diz respeito ao reconhecimento de seus contornos identitários. Prender a atenção à trajetória do primeiro Curso de Dança do Rio Grande do Sul é estimulante para se refletir nos fazeres e saberes que envolvem os projetos político pedagógicos em funcionamento, suas perspectivas e desafios a serem enfrentados no atual contexto de formação acadêmica.

Sob o ponto de vista metodológico, foi perseguido o objetivo de analisar o percurso institucional do Curso de Dança da UNICRUZ (1998-2010), desde a formatação do seu Projeto Político Pedagógico (PPP) por suas fundadoras aos discursos de seus protagonistas no período da sua descontinuidade. Caracterizada como qualitativa, a pesquisa tomou como balizadoras as entrevistas semiestruturadas de seus atores e protagonistas, considerados os mais significativos ao processo de análise da memória individual e memória coletiva.

Ao estabelecer o contraponto entre a memória individual e a memória coletiva, Halbwachs (2013, p. 29) diz que

\footnotetext{
se a nossa impressão pode se basear não apenas na nossa lembrança, mas também na de outros, nossa confiança na exatidão de nossa recordação será maior, como se uma mesma experiência fosse recomeçada não apenas pela mesma pessoa, mas por muitas.
}

Ou seja, cada depoente (entrevistado) expressa uma consciência - um olhar, uma leitura única - de um determinado fato ocorrido, constituindo-se na memória individual, mas seu conjunto - todos os entrevistados - pertence à memória coletiva. São os indivíduos que se lembram, enquanto conjunto de pessoas integrantes do 
grupo, que dão força à duração da memória coletiva. O somatório das lembranças comuns - de cada lembrança individual - seria um ponto de vista sobre a memória coletiva, pondera Halbwachs (2013, p. 69), acrescentando que “[...] este ponto de vista muda segundo o lugar que ali ocupo e que esse mesmo lugar muda segundo as relações que mantenho com outros ambientes".

Ao mencionarmos os integrantes do grupo - aqui entendido como Curso de Dança da UNICRUZ - estes não são personagens fictícios, pois eles existem ou existiram em determinado instante, em cujo grau de pertencimento tem variação quanto ao tempo de permanência e envolvimento no Curso, cuja existência sofreu descontinuidade em um momento de intensa produção acadêmica, por questões político-econômicas e culturais nas quais a Instituição estava envolvida.

Assim, na dança podemos dizer que as relações de força são reduzidas a relações de comunicação, estas sempre relações de poder que dependem na forma e no conteúdo, do poder material ou simbólico acumulado pelos agentes - ou pelas instituições - envolvidas nessas relações, e que podem permitir o acúmulo do poder simbólico. Para Bourdieu (1998, p. 7), em contraposição ao passado, quando não se queria reconhecer o poder nas situações em que ele “[...] entrava pelos olhos a dentro, [...] sem nunca fazer dele, numa outra maneira de o dissolver, uma espécie de circulo cujo centro está em toda parte e em parte alguma”, é preciso saber encontrá-lo onde ele tem menor visibilidade, onde é praticamente irreconhecível. A característica de invisibilidade do poder simbólico, diz Bourdieu (1998, p. 8), permite que este seja exercido “[...] com a cumplicidade daqueles que não querem saber que lhe estão sujeitos ou mesmo que o exercem".

Ao transpor para um contexto atual, onde se presencia num estado de campo o poder por toda parte, vemos as produções simbólicas relacionadas com os interesses dos grupos dominantes. No campo das Artes, o mesmo acontece com a dança, onde as coreografias - mesmo que partindo de um ato criador individual - têm caráter ideológico que serve a interesses particulares que tendem a apresentar como interesses universais, comuns ao conjunto do grupo. A cultura dominante observa 
[...] contribui para a integração real da classe dominante (assegurando uma comunicação imediata entre todos os seus membros e distinguindo-os de outras classes); para a integração fictícia da sociedade no seu conjunto, portanto, à desmobilização (falsa consciência) das classes dominadas; para a legitimação da ordem estabelecida por meio do estabelecimento de distinções (hierarquias) e para a legitimação dessas distinções. (BOURDIEU, 1998, p. 11)

Os diferentes grupos e companhias de dança oferecem um significativo laboratório de análise para mostrar, através de suas coreografias, as diferentes definições do mundo social em conformidade com seus interesses, “[...] e imporem o campo das tomadas de posições ideológicas reproduzindo em forma transfigurada o campo das posições sociais". (BOURDIEU, 1998, p. 11)

Buscou-se em Velho (2003), entender que os sujeitos envolvidos no projeto coletivo que possibilitou a criação e a consolidação do Curso, com a sua descontinuidade, voltaram-se para a construção de seus projetos individuais, que a nova realidade possibilita, pois, para o autor,

\footnotetext{
O projeto no nível individual lida com a performance, explorações, o desempenho e as opções, ancoradas a avaliações e definições da realidade que resultam de complexos processos de negociação e construção que se desenvolvem com e constituem toda a vida social vinculados aos códigos culturais e processos de longa duração. Esses códigos e processos fazem com que os indivíduos estejam em permanente reconstrução porque fazem parte, eles próprios, do processo de construção social da realidade. (VELHO, 2003, p. 28-29, grifo do autor)
}

Na busca da constituição da memória, diversos são os procedimentos que podem ser adotados. A escolha de entrevistar pessoas que participaram das ações e atividades do Curso de Dança da UNICRUZ no seu percurso é justificada pela necessidade de captar informações significativas ainda não documentadas. A opção pela história oral, enquanto metodologia desencadeia novos conhecimentos de um passado próximo. 
Cabe salientar, aqui, a importância de trabalhar com as narrativas quando se

procura compreender e interpretar as manifestações expressadas nos discursos obtidos, nas entrevistas, estabelecendo a forma como histórica e socialmente foram produzidos. Para fundamentar esses pressupostos, foram selecionados aportes teóricos que permitiram a definição dos procedimentos mesmo antes da realização das entrevistas.

Através das entrevistas com ex-alunos, ex-professores e pessoas ligadas à dança que tiveram alguma atuação no e com o Curso, identificou-se questões que procuraram abarcar aspectos da sua criação, da sua finalidade, da sua concepção, do seu contexto e da sua trajetória, registradas e reelaboradas pela memória.

Para a seleção foi necessária uma retomada do universo estudado, identificando o papel e a participação dos entrevistados no Curso, saber quais os mais representativos e reconhecidos pelo grupo. Ainda, como critério de escolha, foi estabelecido que os mesmos estivessem inseridos no mercado de trabalho da dança, quer como professores de ensino formal de educação infantil, básica e superior ou de ensino informal. As entrevistas foram realizadas no período compreendido entre os meses de julho a outubro de 2014, em locais e horários pré-agendados e tiveram um roteiro guiador estabelecido com questões que procuraram delinear o período de existência do Curso.

Para tanto, foram entrevistados nove ex-alunos de um total de 64 egressos, pelo menos um de cada turma formada (7 turmas) e uma ex-aluna portadora de diploma de Educação Física com doutorado, cujo tema é a dança. Cabe ressaltar que dois dos nove ex-alunos foram computados também como ex-professores.

Os professores convidados foram em número de cinco, sendo quatro das disciplinas práticas de dança e, portanto, mais envolvidos com as especificidades e um da área de história para apontar as relações do curso com o contexto institucional e a percepção exógena.

Os terceiros, pessoas envolvidas com o Curso, foram assim convidados: uma das idealizadoras, a pró-reitora de ensino da época da implantação e reconhecimento; três pessoas que participaram como convidados especiais para atuarem 
em atividades e eventos durante a existência do Curso, por mais de duas vezes, bem como uma das avaliadoras do Ministério da Educação (MEC) no processo de seu reconhecimento.

Para a realização das entrevistas foi feito um contato prévio com os depoentes. Uma das terceiras envolvidas, por não haver possibilidade de encontro, se prontificou a responder as questões via email, o que foi considerado importante manter, já que foi uma das proponentes do Curso. Ao tomar conhecimento da possibilidade de conceder sua narrativa, foram esclarecidos os objetivos da investigação e a sua forma de execução. A cessão de direitos das entrevistas foi confirmada através de uma Autorização de Depoimento Oral. No processo de ida a campo, reavivou-se o próprio exercício de escuta, condensando e ampliando o espaço, mas respeitando a expressão e o desejo de quem prestou o depoimento.

Foram reproduzidas todas as entrevistas realizadas, pois se entende que todos os narradores ao se reportarem ao tempo de atuação junto ao Curso de Dança deixaram pistas que ao serem confrontadas entre si apontam as tensões, os movimentos e as percepções de diversos olhares. O total de entrevistas (18) oferece um panorama do caminho inicial da formação superior na área da dança no nosso Estado bem como de suas principais inquietações. Considerou-se o número suficientemente satisfatório e representativo, pois permitiu engendrar uma análise comparativa consistente.

Os depoimentos completos, com suas respectivas transcrições e autorizações, estão sob a guarda do Laboratório de História Oral do Programa de Pós-Graduação em História da Pontifícia Universidade Católica do Rio Grande do Sul (PUC-RS), estando disponibilizados para possíveis consultas.

Além da realização do trabalho com história oral, concomitantemente foi feita uma pesquisa documental e bibliográfica, muitas vezes remetida pelas próprias entrevistas. Para tanto, foram utilizadas diversas fontes que viabilizaram a reflexão sociocultural, para a análise e interpretação dos documentos coletados.

A pesquisa bibliográfica contempla as referências sobre o fenômeno estudado através de publicações acadêmicas na área do ensino superior em dança e da 
dança, de maneira geral. Foram pesquisados periódicos, livros, revistas, dissertações, teses, trabalhos de conclusão de curso, folders, projeto político pedagógico do Curso, documentos oficiais e também consultas na internet. O seu desenvolvimento abrangeu um conjunto de conhecimentos produzidos através desses materiais fundamentando-o. As fontes documentais utilizadas para o estudo foram os relatórios sociais da Universidade e do Curso de Dança; resoluções e documentos disponíveis no arquivo da UNICRUZ; notícias da imprensa da época, dos jornais Diário Serrano, 2 Zero Hora ${ }^{3}$ e Correio do Povo ${ }^{4}$ no período de 1998 a 2010.

Em termos metodológicos, o estudo parte do emprego de depoimentos orais, de documentos escritos e literatura secundária seguindo a metodologia de análise textual de Roque Moraes. Esse método pressupõe etapas de uma análise de conteúdo que é constituída num ciclo de decomposição em três elementos unitarização, categorização e comunicação -, ou seja, a desconstrução do texto, criação de categorias e a interpretação, que resulta em novo significado extraído das mensagens descritas. (MORAES, 2003, p. 191)

Nessas fontes se utiliza o princípio indiciário de Carlo Ginzburg (1990), pelo qual se procura entender o contexto, o surgimento do Curso, a partir das singularidades que funcionam como indicações para o conhecimento de novas realidades, que não são de senso comum ou tradicionais.

Propôs-se um esquema para expressar a trajetória do Curso que pode servir para futuras análises e escrituras de outras instituições. Para tanto, propõe-se um quadro dividido em três fases. A primeira fase trata da contextualização, emergência e implantação do Curso; a segunda fase trata do reconhecimento, avaliação, protagonismo - sua importância e desdobramentos nas atividades artísticas onde está inserido - e, a terceira fase é a da descontinuidade e/ou consolidação e de seus desdobramentos (perfil dos egressos, projetos a partir da atuação no Curso quer como aluno, professor ou colaboradores - os terceiros envolvidos).

2 Jornal com circulação de 3 à domingo, da cidade de Cruz Alta/RS.

3 Jornal diário de circulação estadual.

4 Jornal diário de circulação estadual. 
Esquema para o desenvolvimento da trajetória do Curso:

Quadro 1 - Fases do curso de Dança da Universidade de Cruz Alta

\begin{tabular}{|l|l|l|l|}
\hline Instituição & $\begin{array}{l}\text { Primeira fase } \\
(1994-2000)\end{array}$ & $\begin{array}{l}\text { Segunda fase } \\
(2001-2008)\end{array}$ & $\begin{array}{l}\text { Terceira fase } \\
(2008-2010)\end{array}$ \\
\hline $\begin{array}{l}\text { Curso de Dança } \\
\text { da UNICRUZ }\end{array}$ & $\begin{array}{l}\text { Contexto } \\
\text { Emergência } \\
\text { Implantação }\end{array}$ & $\begin{array}{l}\text { Reconhecimento } \\
\text { Protagonismo } \\
\text { Relação e repercussão } \\
\text { com o meio }\end{array}$ & $\begin{array}{l}\text { Consolidação e/ou } \\
\text { Descontinuidade } \\
\text { Desdobramentos }\end{array}$ \\
\hline
\end{tabular}

Fonte: elaborado pelas autoras.

Os entrevistados foram identificados nas categorias denominadas ex-alunos, ex-professores, e terceiros envolvidos. Nas entrevistas, buscaram-se informações sobre os personagens da história que está sendo analisada e as suas relações com o Curso, entremeando dados obtidos através de referências bibliográficas, documentos e entrevistas. Foram utilizadas as narrativas dos entrevistados e algumas informações adicionais para referenciar suas histórias pessoais e profissionais.

De acordo com as colocações dos entrevistados e retomando, de certa forma, o roteiro das entrevistas realizadas, pretendeu-se tecer e entrecruzar os fatos que constituem a memória do Curso de Dança da UNICRUZ, tarefa complexa por ser uma análise qualitativa, portanto caracterizada como um processo intuitivo, e também pelo processo de transcrição da oralidade para a escrita. Ao interpretar os depoimentos dos entrevistados, perceberam-se algumas colocações diferenciadas quanto à origem do Curso de Dança da UNICRUZ, isto se deve, em tese, aos momentos diferentes que os mesmos estiveram presentes no campo acadêmico.

É pertinente colocar que a formação de profissionais para a docência em dança nem sempre se deu pela universidade, pelo contrário, em sua maioria ocorria e ainda ocorre inicialmente fora dela. A universidade tardiamente recupera essas experiências que nascem fora do seu ambiente, e aí cabe lembrar da formação em dança no Rio Grande do Sul que data da década de 1920, iniciada no Instituto de Cultura Física em Porto Alegre, porém essa formação era basicamente prática, não trabalhava nos moldes da academia. 
Em alguns dos entrevistados que inauguraram o Curso se percebe o forte sentimento de pioneirismo da educação superior em dança e da necessidade desde então de lutar pelo espaço e pela partida, já frustrada em três outras tentativas de início dos trabalhos acadêmicos. Ainda não existia um espaço próprio e definido, a secretaria funcionava junto com a Faculdade de Filosofia Ciências e Letras e a discussão inicial se deu em uma sala nas dependências da Faculdade de Educação Física.

Concomitante à emergência do funcionamento, uma vez formada a primeira turma (Figura 1) e encampada pela reitoria, na ocasião representada por Jacira Cardoso de Moreira e Luis Pedro Bonetti, ela pró-reitora de ensino e ele vice-reitor, imediatamente já foi solicitada uma sala adequada, isto é com espaço amplo, arejada e com piso de madeira para abrandar o impacto dos saltos e quedas dos futuros bailarinos, que vislumbravam a prática imediatamente.

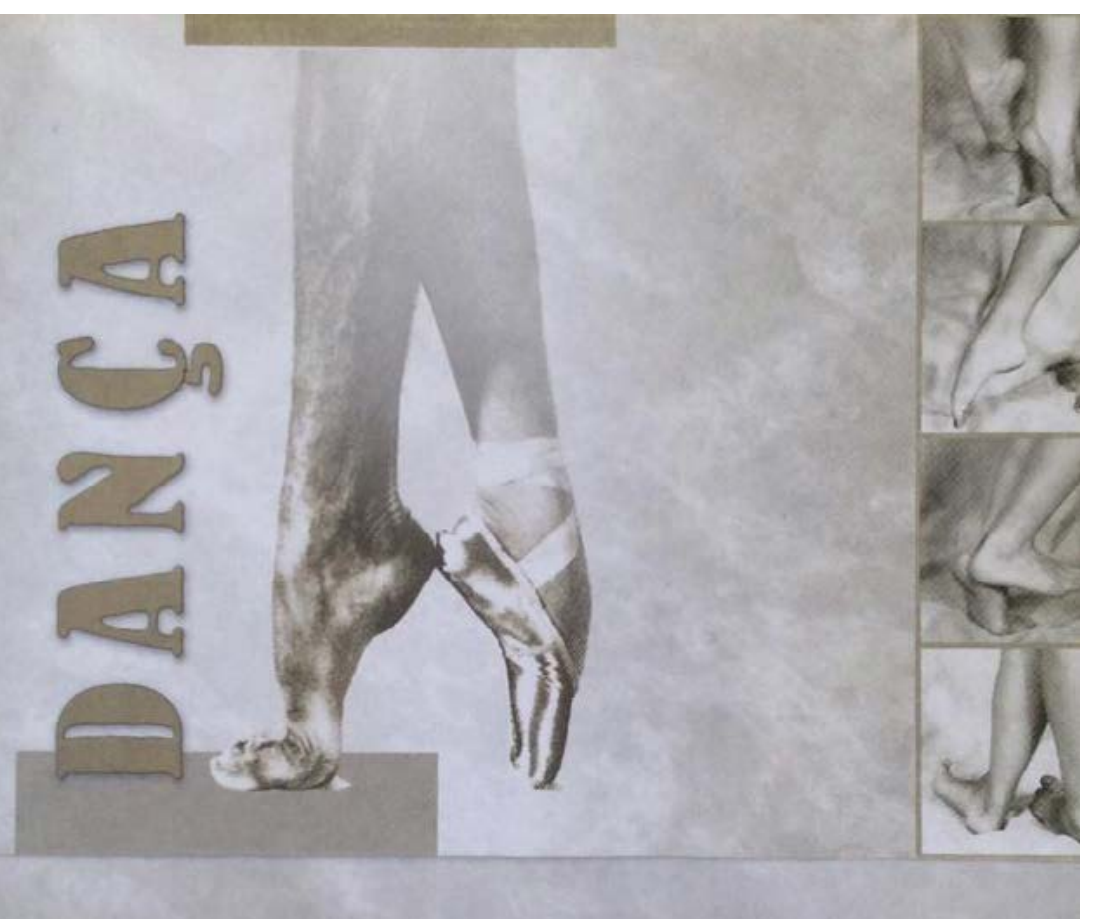

Figura 1 - Convite de FORMATURA DA PRIMEIRA TURMA DO CURSO DE DANÇA UNICRUZ 
A especulação da inauguração do Curso de Dança era evidenciada pela cobertura dos veículos de comunicação da cidade que divulgaram o acontecimento, isto se deve às disputas e o jogo, "será que sai ou não sai?" e isso, foi claro na fala de praticamente todos os entrevistados, sempre era uma batalha atingir o número necessário de candidatos. Isto posto, se percebeu também nas falas a necessidade de aliança interna e representação política em todas as instâncias: os acadêmicos pelo viés da política estudantil, os docentes representados no Conselho Universitário (CONSUN) e Conselho Superior de Ensino, Pesquisa e Extensão (CONSEPE), na época, além da representação externa na Comissão Permanente de Dança e Associação Gaúcha de Dança do Rio Grande do Sul.

O Curso de Dança da UNICRUZ estava inserido em um contexto político, econômico, artístico, social e educacional em que todos buscavam o ensino de qualidade e, junto com isso, buscavam respaldar a busca de legitimação e consolidação profissional. Como foi o primeiro do Estado, atraiu a atenção de profissionais que haviam participado de especializações em dança no exterior e sentiam a necessidade de socializar seus conhecimentos em um ambiente de formação sistematizada, uma vez que na época, não existia um coletivo organizado com demandas dessa natureza. Então se criou um “corredor cultural” entre Cruz Alta - Porto Alegre e Cruz Alta - Santa Maria, pois se primava pela presença de profissionais com conhecimentos específicos nas diferentes áreas que compõem o conhecimento em dança, a saber: dança clássica, cinesiologia, fisiologia, dança moderna, prática docente, corpo e movimento, princípios do movimento, criação artística, música e ritmo, entre tantas, já referenciadas na estrutura curricular do Curso.

Houve também um interesse e um olhar pelas forças políticas do governo que inauguravam possibilidades de criação de políticas públicas para o desenvolvimento das artes, especialmente pelo viés social, para grupos de interesse social. Assim, a década de 2000 se tornou importante para o protagonismo do Curso, pois já existia uma massa crítica de profissionais que discutia a dança em sua complexidade e produzia conhecimento específico, como em nenhum outro lugar do Estado. Ocasião em que grandes expoentes da dança, tanto pelo viés da ciência como: Sylvie Fortin, Isabelle Marteau, Maria Conceição França Rocha, Dicléia Souza, entre outros e, pelo viés da cena: Ana Botafogo, Carlinhos de Jesus, Octávio Nassur, Paulo Caldas, Ana Victória, pessoas articuladas ao meio artístico e 
acadêmico o que permitiu a criação de redes de sociabilidades que influenciaram toda uma geração de profissionais da dança.

Como muitos dos alunos eram estagiários do setor administrativo - secretários, ou ligados à área de projetos de pesquisa e extensão -, eles permaneciam muito tempo conectados com as ações e atividades do Curso. Isso impingiu um sentimento de apropriação e pertencimento, o que rendeu inúmeros projetos de ensino, pesquisa e extensão, além de inúmeros eventos. Tais ações foram evidenciadas nas falas dos entrevistados que, através desses estágios, recebiam subsídios financeiros para viabilizarem a própria mensalidade do Curso.

Nas memórias sobre o princípio do Curso, os sujeitos foram unânimes em ressaltar a importância e a referência que o curso veio a ganhar no Estado. Até os nossos dias ele é referenciado e é digno de elogios pela inauguração na área e por ter preparado o ambiente para novos cursos, inclusive na oferta de profissionais experientes e qualificados. O Curso serviu de estímulo e modelo para a criação de novos cursos de dança nas instituições do Rio Grande do Sul, e estes tendo como docentes ex-alunos e ex-professores da UNICRUZ.

Durante o seu desenvolvimento, o Curso protagonizou diversas atividades, convênios para estágios, apresentações artísticas, encontros, seminários, eventos e semanas acadêmicas, enfim, um movimento que extrapola em muito a carga horária mínima de uma estrutura curricular. Além disso, tanto os professores como os alunos perseguiam a participação em eventos relacionados à dança em diferentes cidades, estados e até países. De certa forma pode-se constatar que essas participações apontaram para os próprios rumos da dança no Brasil.

A UNICRUZ sempre teve um bom relacionamento com a região e participou das ações do Conselho Regional de Desenvolvimento (COREDE) Alto Jacuí. O Curso de Dança sempre esteve acompanhando essa movimentação, através de apresentações artísticas ou ministrando oficinas de dança, com o intuito de ser reconhecido e divulgar suas vagas, sendo um diferencial dentro do contexto de outras instituições. Como falam alguns dos entrevistados, o curso atuava em todas as frentes possíveis, mantendo-se em diálogo constante com a sociedade regional. 
Ao encontrar os balanços sociais da UNICRUZ, percebe-se a inserção das ações do Curso com a questão democrática, como sendo a dança um direito de todos e a dança no berço dos sonhos. Essa ideia desmistifica, de certo modo, a dança entendida como uma atividade luxuosa e como privilégio de poucos. Com isso justifica-se a ideia de que os acadêmicos vinham de diferentes contextos, com ou sem experiência em dança, podendo, através do cumprimento do currículo mínimo, construir seus conhecimentos necessários para a docência em dança e nos diferentes contextos, sentirem-se autorizados e confortáveis para a atividade.

Na preparação de um PPP, para receber a avaliação do MEC, com o cumprimento das novas exigências estabelecidas nas Diretrizes Curriculares para os cursos de dança, houve um movimento de buscar mais profissionais da área específica de dança, o que era raro no Estado. Diversos currículos de professores chegavam à Instituição, mas os que possuíam maior qualificação não tinham tanta conexão com a prática. Considera-se que a composição do quadro docente se deu de forma a contemplar essas questões, e em determinado tempo, após 2002 os próprios egressos que buscavam qualificação já começaram a se inserir no quadro docente.

Um aspecto decorrente das entrevistas é a pouca referência à pesquisa, o que denuncia uma característica do Curso mais voltada para a prática, por isso mais vocacionado para a extensão. O perfil dos alunos e a itinerância dos professores que tinham regime de trabalho parcial, chamados de "horistas", impediam a expansão dessa área que demanda dedicação e orientação intensiva, reflexo das crises econômicas vivenciadas na Instituição.

De acordo com a secretaria acadêmica da Instituição, até2010, o Curso formou 64 licenciados em dança, entre eles, 56 mulheres e 8 homens, aspecto que denuncia a preferência do gênero feminino pelo campo da docência em dança. O total de egressos se dividiu em oito turmas, evidenciando uma média de oito alunos por turma, número este muito aquém da média estabelecida pela política institucional que deveria ter inicialmente 25 alunos matriculados e posteriormente 20 alunos, para tornar-se viável e, que acabou transformando-se no principal fator da descontinuidade do Curso. 
Assim, apesar dos ganhos, foi determinado pelo CONSUN que, se por três vezes consecutivas não houvesse formado turma com o número mínimo de alunos estabelecido pela administração, não seria mais oferecido o Curso e é o contexto em que as licenciaturas se encontram e, assim o Curso entra em processo de descontinuidade: a partir de 2007 não houve mais ingresso.

Percebeu-se nas memórias a indignação, por parte dos entrevistados, em consenso, com o fechamento do Curso. Como estratégia de continuidade, estava com uma nova proposta de ser em regime especial, com algumas disciplinas intensivas nos meses de julho, janeiro e fevereiro, para atrair aqueles interessados que não podiam ficar longe de suas localidades e de seus respectivos trabalhos.

O coletivo estava enfraquecendo, pois havia apenas uma turma em funcionamento e todos os alunos tiveram chance de encerrarem a carga horária através de estratégias que demandou um intenso trabalho da coordenação, professores e os alunos, para que não jubilassem suas caminhadas, no entanto a última formatura, em final de 2010, contou com 12 alunos e, a partir de então não foi mais ofertado e o Curso de Dança foi extinto do rol de cursos da UNICRUZ.

Nas considerações tecidas pelos entrevistados com relação ao fechamento do Curso de Dança, denota-se um sentimento profundo de perda. Porém, considerando a inexistência de demanda, bem como a abertura de outros cursos de dança em instituições de ensino público em diferentes regiões do Estado, o entendimento hoje remete à sensação de que o Curso de Dança da UNICRUZ cumpriu o seu papel de "ponte de ligação" entre um passado informal e a perspectiva de um futuro “ideal”. Deter o olhar na trajetória do ensino da dança na UNICRUZ, estimula à reflexão do fazer político-pedagógico, bem como projetar as novas possibilidades e os desafios a serem enfrentados no atual contexto da formação superior em dança e suas qualificações específicas. 


\section{CONSIDERAÇÕES FINAIS}

O propósito da presente investigação, a partir, principalmente de fonte oral, mas também de documental e de bibliográfica, foi o de compreender o passado a partir das memórias coletivas, de uma procura de sentido, atribuído aos fatos do passado, por aqueles que estavam envolvidos com estes acontecimentos. $\mathrm{O}$ que foi realizado no percurso de 13 anos se pretendeu deixar registrado e analisado neste trabalho.

O Curso seguiu uma trajetória de acordo com as condições da região onde se desenvolveu. Trabalhar com as práticas educativas do Curso de Dança e refletir sobre elas, significou trabalhar com as rupturas e descontinuidades, percebido na análise da trajetória do mesmo, que buscava estimular uma visão sensível e crítica de mundo.

Percebeu-se a pretensão de ampliar a importância da instalação desse Curso, indicando a operacionalização de procedimentos pedagógicos prospectivos e entretecidos para a abertura de outros cursos no Estado. A sua instalação se apresentou como um espaço propício para exercícios provocativos às múltiplas inquietações de alguns profissionais da área.

A produção de informações geradas no ambiente acadêmico e constituídas sob a perspectiva da formação e produção em dança como área de conhecimento, indica a existência de trilhas investigativas que começaram a se abrir. Dessa forma, foi possível tratar de questões antes não abordadas no âmbito acadêmico do ensino da dança, como o trânsito de práticas e teorias, a instalação de outros cursos em instituições públicas, com a perspectiva de estar fomentando processos que perderiam força ou seriam finalizados na colação de grau da turma de 2010, quando o Curso de Dança da UNICRUZ findou.

Procurou-se caracterizar e entender em que sociedade e quais eram as relações dela com a dança e propor: ou se continuava mantendo um modelo esgotado ou se propunha uma estratégia que, na ocasião, foi a de transformar o Curso regular em regime especial - semi-intensivo -, na tentativa de manter qualificando os 
profissionais e dar continuidade ao seu funcionamento. A crise pela qual passava o Curso, já estava instalada e a tentativa não prosperou, o que provocou o seu encerramento em 2010.

O Curso de Dança cumpria um papel importante nas atividades de ensino, pesquisa e extensão. Sempre muito atento às questões próprias da estética da dança nos seus mais diferentes gêneros, da criatividade, da produção de obras, da formação de público, da possibilidade de dialogar com as demais áreas do conhecimento, enfim, conseguiu estabelecer uma troca dinâmica e sistemática com o contexto regional.

Desde sua implantação o Curso de Dança apresentava problemas que o acompanharam todo o seu tempo, a importância da formação em dança parecia ter que acontecer por convencimento. Ainda era estranha a ideia para a identificação do profissional criado naquele momento e que não tinha ainda um campo profissional definido que o demandasse. Os concursos na área de ensino da dança eram escassos. A atividade era desempenhada por profissionais sem formação acadêmica e mais voltada para o entretenimento. Além disso, demanda reprimida, se dava pelo fato de a Universidade de Cruz Alta ser particular/comunitária e estar localizada no interior do Estado do Rio Grande do Sul.

Atualmente é possível perceber uma mobilização e a preocupação em aumentar a massa crítica de produção em dança para avançar nos cursos de qualificação, especialmente as pós-graduações, pois diversos fóruns e encontros estão sendo realizados em todo o país. Um fator importante de registrar aqui é que o ensino superior em dança no Rio Grande do Sul se expandiu em diversos lugares e está atendendo as demandas de cada região, qualificando e profissionalizando as pessoas que buscam na dança a sua forma de viver. Baseada no significado histórico já instituído, com a ciência de que o desafio acompanha a contemporaneidade, a área de dança na UNICRUZ sempre buscou se voltar para a qualificação profissional integrada com as instâncias afins.

Como em uma coreografia que se movimenta, o retorno ao Curso, ora se aproximando, ora se distanciando, suscitou uma prazerosa maneira de interpretar e ir construindo aos poucos as suas reminiscências. Porém, o caminho de volta não é um simples retorno. Pois já se avançou, é outro começo, diferente do inicial. 
E, é esta tensão que dificulta problematizar o estabelecido e pensar, ao mesmo tempo, nas diferentes faces do problema construído. Procurou-se apresentar a trajetória do Curso nas suas diferentes fases e, desta forma, dar luz aos questionamentos que poderiam suscitar maiores aprofundamentos.

Para concluir a investigação se retornou às principais questões que foram instigadas e rememoradas pelos entrevistados, reconhecendo que é impossível se dar conta de todo o universo narrado, um sentimento de algumas perdas no trajeto, talvez da passagem do oral para o escrito. Enfim, considerou-se que os resultados apresentados foram significativos e, também, desafiantes para o entendimento dos caminhos percorridos pelo Curso de Dança da UNICRUZ, ensejando uma constante discussão sobre a formação superior em dança no Rio Grande do Sul, pois tudo poderá ser retomado, criticado e aprofundado. Esse é o resultado mais gratificante quando se pensa e se está no ambiente acadêmico.

\section{REFERÊNCIAS}

ALBERTI, Verena. Histórias dentro da História. In: PINNSKY, Carla Bassanezi (org.). Fontes Históricas. São Paulo: Contexto, 2005.

ALIANÇA, Priscila. Pesquisa (auto) biográfica e (auto)formação crítica do professor de Língua Inglesa. Holos, Natal, Ano 27, v. 4, p. 201-214, 2011.

BOURDIEU, Pierre. O poder simbólico. Rio de Janeiro: Bertrand Brasil, 1998.

CAMARGO, Maria Aparecida Santana. et al. (org.) Pesquisa na universidade: mosaico de vivências acadêmicas. Cruz Alta: UNICRUZ, 2012.

CERBINO, Ana Beatriz. História da dança: considerações sobre uma questão sensível. In: PEREIRA, R.; SOTER, S. (org.). Lições de Dança 5. Rio de Janeiro: UniverCidade Editora, 2005.

CHARTIER, Roger. Cultura escrita, literatura e história. conversas de Roger Chartier com Carlos Aguirre Anaya, Jesús Anaya Rosique, Daniel Goldin e Antonio Saborit. Tradução de Ernani Rosa. Porto Alegre: ARTMED Editora, 2001.

CONSTANTINO, Núncia Santoro de. Teoria da história e a reabilitação da oralidade: convergência de um processo. Pesquisa. In: ABRAHÃO, Maria Helena Menna Barreto (org.). A aventura(auto) biográfica: fundamentos e metodologia. Porto Alegre: EDIPUCRS, 2004. 
MORAES, Roque. Uma tempestade de luz: a compreensão possibilitada pela análise textual discursiva. Ciência \& Educação, Bauru, v. 9, n. 2, p. 191-211, 2003.

PORTELLI, Alessandro. Ensaios de história oral. São Paulo: Letra e Voz, 2010.

STRAZZACAPPA, Márcia. Dançando na chuva ...e no chão de cimento. In: FERREIRA, Sueli (org.). O ensino das artes: construindo caminhos. 10. ed. Campinas, SP: Papirus, 2012.

UNIVERSIDADE DE CRUZ ALTA. Projeto Político-Pedagógico do Curso de Dança. Cruz Alta, 2007.

VELHO, Gilberto. Projeto e metamorfose: antropologia das sociedades complexas. Rio de Janeiro: Jorge Zahar, 2003.

Carmen Anita Hoffmann: é formada em Arquitetura e Urbanismo pela Universidade do Vale do Sinos (Unisinos) e Esquema I na Universidade de ljuí (Unijuí) com mestrado e doutorado em História na Pontifícia Universidade Católica do Rio Grande do Sul (PUC-RS). Professora e coordenadora do Curso de Dança-Licenciatura e do Programa de Pós-graduação em Artes Visuais da Universidade Federal de Pelotas (UFPel). Vice-líder do grupo de pesquisa Observatório de Memória, Educação, Gesto e Arte (OMEGA).

Andrisa Kemel Zanella: é professora dos cursos de Dança-Licenciatura e Teatro-Licenciatura da Universidade Federal de Pelotas (UFPel), pedagoga e bacharel em Artes Cênicas, doutora em Educação pela Universidade Federal de Pelotas. É vice-líder do Grupo de Estudos e Pesquisa sobre Imaginário, Educação e Memória (GEPIEM/UFPel/RS) e pesquisadora colaboradora do Grupo de Estudos e Pesquisa em Educação e Imaginário Social (GEPEIS/UFSM/RS).

Débora Souto Allemand: é doutoranda em Artes Cênicas na Universidade Federal do Rio Grande do Sul (UFRGS). Arquiteta e urbanista, licenciada em Dança e mestra em Arquitetura e Urbanismo pela Universidade Federal de Pelotas (UFPel). Foi professora substituta no curso de Dança-licenciatura da UFPel de 2016 a 2018 e atualmente é professora de Arte no município de Pelotas. Pesquisadora no Grupo de Pesquisa Observatório de Memória, Educação, Gesto e Arte (OMEGA). 